1 Wiener AS, Peters HR. Haemolytic reactions following transfusions of blood of the homologous group, with three cases in which the same agglutinogen was responsible. Ann Intern Med 1940;13:2306-21

2 Levine $\mathbf{P}$, Katzin EM, Burnham L. Isoimmunization in pregnancy, its possible bearing on the tiology of erythroblastosis fetalis. JAMA 1941;116:825-6.

3 Finn R, Clarke CA, Donohoe WTA, et al. Experimental studies on the prevention of $\mathrm{Rh}$ haemolytic disease Br Med f $1961 ;$; $1486-90$.

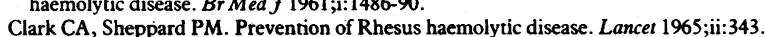

5 Freda VJ, Gorman JG, Pollack W, Robertson JG, Jennings ER, Sullivan JF. Prevention of Rh isoimmunization. FAMA 1967;119:390-4.

6 Tovey LAD. Haemolytic disease of the newborn-the changing scene. $\operatorname{Br} \mathcal{J}$ Obste Gynaecol 986;93:960-6.

Giblett ER. Blood group alloantibodies: an assessment of some laboratory practices. Transfusion 1977;17:299-308.

8 Beal RW. Non-rhesus (D) blood group isoimmunization in obstetrics. Clin Obstet Gynaecol 1979;6:493-508.

Hardy J, Napier JAF. Red cell antibodies detected in antenatal tests on Rhesus positive women in South and mid Wales, 1948-1978. Br f Obstet Gynaecol 1981;88:91-100.

10 Bowell PJ, Allen DL, Entwistle CC. Blood group antibody screening tests during pregnancy. $\mathrm{Br} \mathcal{F}$ Obstet Gynaecol 1986;93:1038-43.

1 Bowell PJ, Brown SE, Dike AE, Inskip MJ. The significance of anti-c alloimmunization in pregnancy. Brf Obstet Gynaecol 1986;93:1044-8.

12 Griffith TK. The irregular antibodies-a continuing problem. Am $\mathcal{f}$ Obstet Gynecol 1980;137; $174-5$.

13 Yoshida Y, Yoshida H, Tatsumi K, Asoh T, Hoshino T, Matsumoto A. Successful antibody elimination in severe $M$-incompatible pregnancy. $N$ Engl $\mathcal{Y}$ Med 1981;305:460-1.

4 Dacus JV, Spinnato JA. Severe erythroblastosis fetalis secondary to anti-Kpb sensitization. Am $\mathcal{J}$ Obstet Gynecol 1984;150:888-9.

15 Astrup J, Kornstad L. Presence of anti-c in the serum of 42 women giving birth to $c$ positive babies: Serological and clinical findings. Acta Obstet Gynecol Scand 1977;56:185-8.

\section{Acute renal failure: diagnosis of cause needed within hours}

Doctors may be so busy treating patients with acute renal failure with fluid and electrolyte replacement and, if necessary, dialysis that they may forget the importance of reaching an early diagnosis of the cause of the renal failure. This amnesia may cost patients their chance of having their renal failure reversed.

A recent prospective study of 250 patients with acute renal failure reminds us of the importance of making a histological diagnosis in those patients in whom specific treatment begun early might lead to reversal of acute renal failure. ${ }^{1}$ The proportion of patients with medical causes of acute renal failure appears to be rising, and it is these patients who will benefit most from early diagnosis by renal biopsy. ${ }^{23}$ Immunosuppressive treatment may be indicated in those with necrotising or crescentic glomerulonephritis, and recovery of renal function seems more likely if specific treatment is started before oliguria or anuria occur..$^{2.5}$

The suggestion that early diagnosis of medical acute renal failure by renal biopsy may help in managing acute renal failure is not new, ${ }^{2}$ but the recent finding that such an approach may lead to a histological diagnosis in up to a quarter of patients with acute renal failure presenting to a specialist unit suggests that the doctors responsible for the initial care of patients in a general ward should urgently determine whether a patient needs a biopsy. ${ }^{1}$ Carefully examining the clinical, nursing, and anaesthetic records plus examining the urine and excluding obstructive uropathy (by ultrasonography if necessary) will identify the $40-50 \%$ of patients with surgical renal failure and the few with obstetric renal failure. Clinical clues to glomerulonephritis may be rare in the remainder, although dipstick tests and microscopic examination of the urine may show the proteinuria, haematuria, and casts that point to this possibility. Renal biopsy in these patients is urgent, and they should be transferred to a specialist unit.

The reduced proportion of surgical and obstetric patients with acute renal failure probably reflects the recognition by anaesthetists of factors, such as fluid depletion, that predispose to acute renal failure. Further encouragement about the prognosis in this group of patients comes from evidence that the survival of patients with acute renal failure after repair of abdominal aortic aneurysms can be almost as good as that of all patients with surgical acute renal failure. ${ }^{1}$ The mortality from acute renal failure is appreciably higher in patients requiring mechanical ventilation and in those with sepsis and cardiorespiratory failure. Searching diligently for, and treating, foci of infection and avoiding measures that may precipitate cardiorespiratory failure early in the course of acute renal failure may help to reduce mortality.

The overall survival from acute renal failure has changed little in the past 20 years, although the range of underlying disease has changed appreciably. The increasing proportion of patients with medical acute renal failure calls for close collaboration between general physicians and specialist units. Failure to begin this collaboration within one or two hours of admitting a patient with acute renal failure to a general ward may deny him the chance of reversing his acute renal failure. The recent evidence that the mortality from medical acute renal failure may be lower than that from surgical acute renal failure provides strong support for management that places an emphasis on early diagnosis.

Physician, BUPA Hospital,

DAVID J WARREN

Havant PO9 5NP

1 Beaman M, Turney JH, Rodger RSC, McGonigle RJS, Adu D, Michael J. Changing pattern of acute renal failure. $O \mathcal{F} M e d$ (in press)

2 Wilson DM, Turner DR, Cameron JS, Ogg CS, Brown CB, Chantler C. Value of renal biopsy in acute intrinsic renal failure. Br.Med $\mathrm{f}$ 1976;ii:459-61.

3 Beaufils M, Morel-Maroger L, Sraer J, Kanfer A, Kourilsky O, Richet G. Acute renal failure of glomerular origin during visceral abscesses. N Engl f Med 1976;295:185-8.

4 Heaf JG, Jorgensen F, Nielsen LP. Treatment and prognosis of extracapillary glomerulonephritis. Nephron 1983;35:217-24.

5 Courser WG. Idiopathic rapidly progressive glomerulonephritis. Am f Nephrol 1982;2:57-69.

\section{Tenosynovitis in industry: menace or misnomer?}

Tenosynovitis affecting the hand or forearm is now the second commonest prescribed industrial disease in Britain (the commonest is dermatitis). ${ }^{2}$ It is not always appreciated, however, that there are two distinct conditions commonly described as tenosynovitis that differ in their incidence, symptoms, signs, treatment, and prognosis. ${ }^{3.5}$ The first of these could be called true tenosynovitis-that is, inflammation of the synovial lining of a tendon sheath - and is rare and potentially serious. The second, which is known generally as peritendinitis crepitans, is inflammation at the musculotendinous junction that often extends well into the affected muscle..$^{3-6}$ It is more common and much more benign. Assembly line workers who repeat the same movements up to 25000 times a day are vulnerable to both conditions. ${ }^{7-9}$ The incidence is difficult to establish as many studies do not state their diagnostic criteria, but most accept that true tenosynovitis is much less common than peritendinitis crepitans. ${ }^{2-59}$ The incidence of the latter varies considerably between different occupations from under $1 \%$ to over $50 \%{ }^{3}$

Both conditions are painful (particularly on resisted movement), and there is usually localised swelling, tenderness, and audible or palpable crepitus. The distinguishing feature is the site of the lesion: true tenosynovitis affects the synovial sheaths and is thus confined to the wrist and hand, where 